\title{
Left ventricular aneurysm as a coronary risk factor independent of overall left ventricular
}

\author{
function
}

\begin{abstract}
Patients with left ventricular aneurysm (LVA) have been shown to have a higher mortality rate than those with normal left ventricular function. The purpose of this study was to determine whether or not LVA, in patients with coronary artery disease, is a risk factor independent of left ventricular function. Thirty-nine patients with anglographically demonstrated segmental dyskinesis (LVA group) were retrospectively compared to 28 patients with segmental akinesis and ejection fraction less than $60 \%$ (control group). There was no significant difference in age, ejection fraction, severity of coronary artery disease, cardiac index, or frequency of cardiac surgery between the two groups. Compared to control subjects, the LVA group had a significantly higher left ventricular end-diastolic pressure and greater tendency to have apical involvement. Although electrocardiography, echocardiography, and radioventriculography were each highly specific, their sensitivities were only $40 \%$ to $60 \%$. Follow-up data were available for a mean of 33 months after catheterization. No significant benefit from aneurysmectomy could be demonstrated. There was an insignificant trend in the LVA group toward more severe congestive heart fallure and less angina. There was no significant difference in the reinfarction rate, incidence of ventricular tachycardia, or embolism. Mortality rate was $38 \%$ in the LVA group and $32 \%$ in the control group $(p=0.59)$. We conclude that LVA is not an independent risk factor for congestive heart failure, angina, ventricular tachycardia, reinfarction, embolism, or death. (AM HeART J 111:23, 1986.)
\end{abstract}

David E. Cohen, M.D., and Robert A. Vogel, M.D. Ann Arbor, Mich.

Left ventricular aneurysm (LVA) is a common sequela to myocardial infarction, occurring in $10 \%$ to $30 \%$ of patients surviving an acute myocardial infarction. ${ }^{1-3}$ Many studies have shown that patients with LVA have a higher mortality rate than those with normal left ventricular function ${ }^{4,5}$ and have suggested that these patients are particularly susceptible to severe ventricular arrhythmias, ${ }^{6-10}$ thromboembolic phenomena, ${ }^{1,7,10}$ and congestive heart failure. ${ }^{1,5,7,9-11}$

Surgical resection of LVA has been commonly performed in an effort to treat these problems, and many studies suggest improvement in survival rate and functional status after aneurysmectomy or aneurysmorrhaphy., 10,12-20 However, these procedures are associated with a high operative mortality rate, and there have been no controlled, randomized, prospective studies on the efficacy of these proce-

From the Division of Cardiology, University of Michigan Medical Center.

Received for publication Jan. 14, 1985; revision received June 17, 1985; accepted July 15, 1985.

Reprint requests: Robert A. Vogel, M.D., Cardiology Section, Veterans Administration Medical Center, 2215 Fuller Rd., Ann Arbor, MI 48105. dures. Furthermore, it is not clear whether the morbidity and mortality associated with LVA are the result of the segmental dysfunction itself or can be attributed to the severe overall left ventricular dysfunction with which it is often associated. The purpose of this study was to determine whether or not LVA is an independent risk factor for cardiac morbidity and mortality in patients with coronary artery disease.

\section{METHODS}

Patient selection. All cardiac catheterizations $(n=895)$ performed at the University of Michigan Hospital between January 1, 1978, and December 31, 1979, were reviewed. LVA was defined as any dyskinetic (outward systolic motion) segment of the left ventricle. All patients with such an abnormality on ventriculography were selected for study (LVA group). The control group consisted of all patients with akinetic segment(s) of the left ventricle (no systolic motion), ejection fraction of less than $60 \%$, and no areas of dyskinesis.

Excluded from these patients were those with greater than a $15 \mathrm{~mm} \mathrm{Hg}$ gradient across the aortic valve (two patients in the control group and one in the LVA group), those with mitral valve areas less than $1.0 \mathrm{~cm}^{2}$ (two patients in the control group), and those with greater than 
Table I. Clinical characteristics of aneurysm and control patients at time of catheterization*

\begin{tabular}{lccc}
\hline & $\begin{array}{c}\text { Aneurysm } \\
\text { group }\end{array}$ & $\begin{array}{c}\text { Control } \\
\text { group }\end{array}$ & p Value \\
\hline No. of patients & 39 & 28 & \\
Mean age (years \pm SD) & $58 \pm 9$ & $58 \pm 9$ & NS \\
Male/female & $74 / 26$ & $89 / 11$ & NS \\
History & & & \\
$\quad$ Previous MI & 92 & 86 & NS \\
CHF & 42 & 25 & NS \\
Angina & 88 & 86 & NS \\
VT & 10 & 18 & NS \\
Embolism & 3 & 14 & NS \\
Physical examination & & & \\
Rales & 37 & 21 & NS \\
Abnormal PMI & 37 & 25 & NS \\
S & 18 & 36 & $<0.05$ \\
$S_{4}$ & 68 & 40 & $<0.05$ \\
Murmur & 26 & 53 & $<0.05$ \\
Edema & 21 & 4 & $<0.05$ \\
JVD & 16 & 4 & NS \\
\hline
\end{tabular}

Abbreviations $\mathrm{SD}=$ standard deviation; $\mathrm{NS}=$ not significant; $\mathrm{MI}=$ myocardial infarction; $\mathrm{CHF}=$ congestive heart failure; $\mathrm{VT}=$ ventricular tachycardia; $\mathrm{PMI}=$ point of maximal impulse; $\mathrm{S}_{3}=$ third heart sound, $S_{s}=$ fourth heart sound; JVD = jugular venous distention.

*Data are expressed as percentage of group with each characteristic unless otherwise indicated.

$1+$ mitral or aortic insufficiency (one patient in the LVA group). Also excluded were those with ventricular septal defect (one in the LVA group), those without at least a $70 \%$ stenosis of at least one major coronary artery (one in the control group), those who died during cardiac catheterization (two in the LVA group), those for whom medical records were unavailable (two in each group), those in whom no coronary angiography was performed (one in the control group), and those who had undergone previous cardiac valve replacement (one in each group). There are 23 patients with akinesis who were excluded because of ejection fractions $>60 \%$. Three patients had undergone previous coronary artery bypass surgery at the time of entry into the study (two in the LVA group and one in the control group). After these patients were excluded, the LVA group contained 39 patients and the control group, 28 patients. In the LVA group, four patients had 1+ mitral insufficiency, one had a $10 \mathrm{~mm} \mathrm{Hg}$ aortic valve gradient, and one had $1+$ aortic insufficiency. In the control group, one patient had a $10 \mathrm{~mm} \mathrm{Hg}$ aortic valve gradient, one had $1+$ mitral insufficiency, and one had 1+ aortic insufficiency.

Catheterization data. Catheterization reports on all selected patients were reviewed, and the following data were obtained: left ventricular end-diastolic pressure, cardiac index, coronary angiographic findings, left ventricular ejection fraction, and quantification of motion of each left ventricular segment (anterobasal, anterolateral, apical, inferior, posterobasal, lateral, and septal) as either normal, hypokinetic, akinetic, or dyskinetic. Ventriculograms were reviewed by an independent observer if the
Table II. Noninvasive data at time of catheterization*

\begin{tabular}{lccc} 
& $\begin{array}{c}\text { Aneurysm } \\
\text { group }\end{array}$ & $\begin{array}{c}\text { Control } \\
\text { group }\end{array}$ & p Value \\
\hline ECG & & & \\
$\quad$ AMI & 49 & 18 & + \\
IMI & 21 & 44 & + \\
$\quad$ AMI and IMI & 13 & 15 & NS \\
$\quad$ No MI & 18 & 22 & NS \\
$\quad$ ST segment elevation & 41 & 15 & $<0.05$ \\
Chest X-ray & & & \\
$\quad$ Cardiomegaly & 33 & 7 & $<0.05$ \\
$\quad$ LV enlargement & 8 & 11 & NS \\
Radionuclide ventriculogram & & & \\
$\quad$ Segmental dyskinesis & 48 & 8 & $<0.05$ \\
Two-dimensional echocardiogram $\ddagger$ & & \\
$\quad$ Segmental dyskinesis & 67 & 33 & NS \\
\hline
\end{tabular}

Abbreviations: $\mathrm{AMI}=$ anterior myocardial infarction; $\mathrm{IMI}=$ inferior myocardial infarction; $\mathrm{MI}=$ myocardial infarction; $\mathrm{LV}=$ left ventricle; NS = not significant.

*Data are expressed as percentage of group with each characteristic. $t p$ Value for observed distribution of AMI and IMI is 0.07 .

$\ddagger$ Echocardiograms were performed in only six aneurysm patients and three control patients.

catheterization report data were ambiguous or inconsistent. All of the ventriculograms were technically adequate and had sufficient opacification for determination of regional and global wall motion. Ejection fractions were measured on sinus beats only. Postectopic beats were excluded for analysis unless these were the only sinus beats available. A vessel was considered diseased if a stenosis of at least $70 \%$ was present.

Clinical data. The medical record of each patient was reviewed. History and physical examination obtained at the time of cardiac catheterization were used to determine the presence of previous myocardial infarction, the presence and severity of angina and congestive heart failure, the presence of ventricular arrhythmias and thromboembolic phenomena, the presence of cardiac risk factors, and evidence of abnormal cardiac physical findings. Each patient had a standard 12-lead ECG and a chest $\mathbf{x}$-ray prior to catheterization. Forty patients underwent multiple-gated acquisition radionuclide ventriculograms using in vivo labeled red blood cells and 16 frames/cardiac cycle gating. Several patients had other diagnostic studies including exercise tests, ambulatory ECG monitoring, radionuclide ventriculography, thallium perfusion studies, and invasive electrophysiologic studies, all of which were also recorded.

The follow-up period was defined as commencing with the day following cardiac catheterization and ending with the most recent available date of follow-up or death. Data pertaining to this period were obtained from the medical records, by contact with the patients' physicians, or by contact with the patients themselves or their surviving family. Information specifically sought included the performance of cardiac surgery, presence and severity of angina pectoris, congestive heart failure and ventricular arrhythmias, the presence of thromboembolic phenome- 
na, and death. If death occurred, information concerning the cause of death was obtained.

Statistical comparisons between the akinetic and dyskinetic groups were made by means of Student's unpaired $t$ test for continuous variables and chi square with continuity correction for discrete variables.

\section{RESULTS}

Clinical data at the time of catheterization. The demographic, historic, and physical examination data obtained at the time of catheterization in each group are summarized in Table I. There were no statistically significant differences between the two groups with respect to age, sex, and cardiac morbidity. The prevalence of cardiac risk factors was similar in both groups. Third and fourth heart sounds and peripheral edema were more common in the LVA group than in the control group.

Noninvasive data at the time of catheterization. ECG and chest $x$-ray findings are summarized in Table II. There was a trend to more old anterior myocardial infarctions in the aneurysm group, which approached statistical significance. The presence of ST segment elevation was very specific for LVA but was only present in a minority of patients with this lesion. The prevalence of cardiomegaly on chest $x$-ray was significantly higher in the LVA group.

Radionuclide ventriculography was performed in 27 patients in the LVA group and in 13 in the control group. Dyskinetic segments were seen in $48 \%$ of the LVA patients studied and in $8 \%$ of the control patients studied. The single patient in the control group with dyskinesis shown by radionuclide study was alive and free of cardiovascular events 42 months after catheterization and should not alter the conclusions of this study even if the patient might be considered misclassified. Four of the six patients in the LVA group who underwent twodimensional echocardiography were found to have evidence of segmental dyskinesis, whereas only one out of three control patients had this echocardiographic finding.

Catheterization data. The finding of cardiac catheterization are outlined in Table III. The two groups were well matched for mean ejection fraction ( $43 \%$ in the LVA group, $45 \%$ in the control group) and the extent and distribution of coronary artery disease. There was a significantly higher mean left ventricular end-diastolic pressure in the LVA group and a lower mean cardiac index which approached statistical significance. The distribution of dyskinetic segments in the LVA group was markedly different from the distribution of akinetic segments in the control group, with the apex more frequently
Table III. Cardiac catheterization data*

\begin{tabular}{lrcc}
\hline & $\begin{array}{c}\text { Aneurysm } \\
\text { group }\end{array}$ & $\begin{array}{c}\text { Control } \\
\text { group }\end{array}$ & p Value \\
\hline Mean EF ( $\pm \mathrm{SD})$ & $43 \pm 20$ & $45 \pm 15$ & $\mathrm{NS}$ \\
Mean LVEDP (mm Hg $\pm \mathrm{SD})$ & $18.1 \pm 6.7$ & $14.3 \pm 6.3$ & $<0.05$ \\
Mean CI (L/m/m $\pm \mathrm{SD})$ & $2.5 \pm 0.6$ & $2.8 \pm 0.4$ & 0.07 \\
Severity of CAD & & & \\
Single-vessel disease & 20 & 7 & \\
Double-vessel disease & 13 & 7 & \\
Triple-vessel disease & 67 & 86 & \\
Distribution of CAD & & & \\
LAD & 95 & 96 & $\mathrm{NS}$ \\
RCA & 77 & 93 & $\mathrm{NS}$ \\
LCX & 64 & 85 & $<0.05$ \\
LMCA & 5 & 11 & $\mathrm{NS}$ \\
Wall motion abnormalities $\dagger$ & & & \\
Apex & 84 & 43 & $<0.05$ \\
Anterolateral & 23 & 28 & $\mathrm{NS}$ \\
Inferior & 15 & 54 & $<0.05$ \\
Posterobasal & 5 & 43 & $<0.05$ \\
Lateral & 0 & 11 & $<0.05$ \\
Septal & 5 & 14 & $\mathrm{NS}$ \\
\hline
\end{tabular}

Abbreviations: $\mathrm{EF}=$ ejection fraction; $\mathrm{LVEDP}=$ left ventricular end diastolic pressure; $\mathrm{CI}=$ cardiac index; $\mathrm{CAD}=$ coronary artery disease; $\mathrm{LAD}=$ left anterior descending artery; $\mathrm{RCA}=$ right coronary artery; LCX = left circumflex artery; LMCA = left main coronary artery; $\mathrm{NS}=$ not significant.

*Data are expressed as percentage of group with each characteristic unless otherwise specified.

$\dagger$ These figures represent the distribution of dyskinetic segments in the aneurysm group and akinetic segments in the control group.

involved in the former group and inferior, posterobasal, and lateral wall involvement more frequent in the latter group.

Follow-up data. The mean duration of follow-up was $33 \pm 19$ months in the LVA group (range 1 to 55 months) and $31 \pm 13$ months in the control group (range 1 to 47 months) $(p=0.67)$. Cardiac surgery was performed during the follow-up period in 17 $(44 \%)$ patients in the LVA group and in $12(43 \%)$ patients in the control group. In all except one patient (who had an aneurysmectomy only), all procedures consisted of coronary artery bypass grafting with an average of 1.8 bypasses/patient in the LVA group and 2.5 bypasses/patient in the control group. Twelve LVA patients underwent concomitant (or isolated in one patient) aneurysmectomy or aneurysmorrhaphy. No valve replacements were performed, reflecting the exclusion of patients with significant valvular disease. The operative mortality rate, defined as death within 24 hours of surgery, was 4 out of 17 LVA patients $(23 \%)$ and 1 out of 12 control patients $(8.3 \%)$. The outcome of medical and surgical therapy in both groups is outlined in Fig. 1.

In an attempt to ascertain the effect of aneurys- 

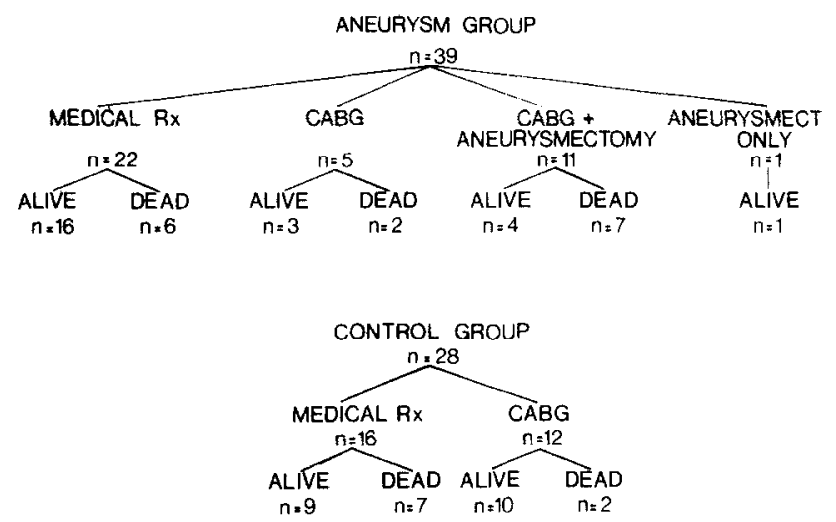

Fig. 1. Clinical outcome of surgical and medical management in aneurysm and control groups. $n=$ number of patients; $R x=$ treatment; $C A B G=$ coronary artery bypass graft.

mectomy or aneurysmorrhaphy on symptoms of congestive heart failure, Fig. 2 compares the initial and follow-up functional status in LVA patients who underwent this procedure with those aneurysm patients who did not. No clear benefit from this procedure could be demonstrated. The overall mortality rate in the resected group was $58 \%$ compared to $30 \%$ in the unresected group.

Clinical status at the most recent time of followup or at the time just prior to death is outlined in Table IV. The frequency of clinically evident congestive heart failure, angina, ventricular tachycardia, recurrent myocardial infarction, and cerebrovascular events as not significantly different between the two groups. In neither group was an event identified that was clearly embolic in origin. Many of the patients who experienced a cerebrovascular event had known cerebrovascular disease. None of the patients was on chronic anticoagulation therapy during the study.

When angina and congestive heart failure were graded by New York Heart Association criteria and the two groups compared according to the severity of these symptoms, there was no statistically significant difference between these two groups (Fig. 3).

The mortality rate was $38 \%$ in the LVA group and $32 \%$ in the control group, a difference which is not statistically significant $(p=0.59)$. Among patients in the LVA group, the causes of death were cardiac in 11 (one sudden death, four congestive heart failure, two ventricular arrhythmia, and four recurrent myocardial infarction), noncardiac in one (cancer), and undetermined in three. Among control paitents, the causes of death were cardiac in five (one congestive heart failure, two ventricular arrhythmia, and two recurrent myocardial infarction), noncardiac in three (chronic obstructive pul-

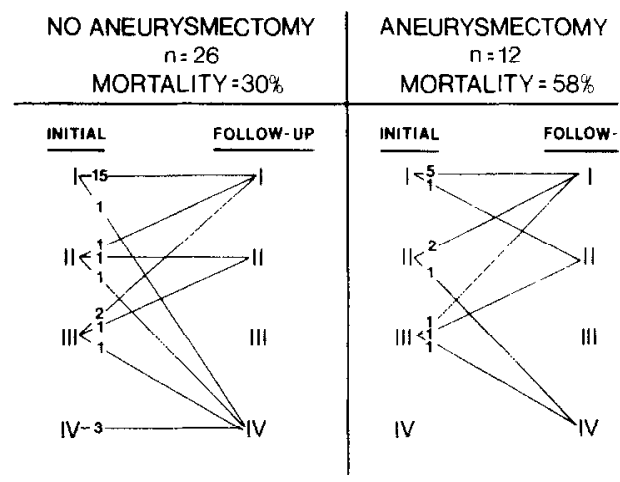

Fig. 2. Severity of congestive heart failure symptoms (New York Heart Association classification) in aneurysm patients at the time of catheterization (Initial) and at the time of latest follow-up. Patients who died during this interval are classified according to the most recent status while alive. Numbers represent the number of patients represented by each line. Left, Patients who did not undergo left ventricular aneurysmectomy during this interval. Right, Patients who underwent left ventricular aneurysmectomy during this interval.

monary disease, cancer, and cirrhosis), and undetermined in one patient.

When death, myocardial infarction, and cerebrovascular accidents were grouped together as endpoint events, there was still no significant difference between the two groups (mean incidences: $20.3 \%$ in the LVA group and $16.7 \%$ in the control group).

\section{DISCUSSION}

That global left ventricular dysfunction is a major prognostic indicator in patients with ischemic heart disease has been well established. Whether or not segmental left ventricular function has the same significance, independent of ejection fraction, has not been determined. LVA, the most advanced form of segmental dysfunction, is often associated with global dysfunction and, therefore, may not be specifically responsible for the increased morbidity and mortality often attributed to it.

Earlier studies. Only two other studies have examined the prognostic significance of LVA independent of overall left ventricular function., ${ }^{41}$ Faxon et al., ${ }^{4}$ by means of data obtained from the Coronary Artery Surgery Study, found that the higher 4-year mortality rate in patients with LVA (defined as dyskinesis or akinesis), as compared to patients without LVA, was no longer demonstrable when the LVA patients were compared to patients without LVA but with similar degrees of residual or total left ventricular dysfunction. Meizlish et al. ${ }^{21}$ recently examined the prognostic significance of LVA defined by radionuclide angiography as dyskinesis 
Table IV. Clinical status at time of latest follow-up*

\begin{tabular}{lccc}
\hline & $\begin{array}{c}\text { Aneurysm } \\
\text { group }\end{array}$ & $\begin{array}{c}\text { Control } \\
\text { group }\end{array}$ & p Value \\
\hline CHF & 32 & 29 & NS \\
Angina & 50 & 71 & NS \\
Recurrent MI & 18 & 7 & NS \\
Ventricular tachycardia & 16 & 4 & NS \\
CVA or TIA & 5 & 11 & NS \\
Death & 38 & 32 & NS \\
\hline
\end{tabular}

Abbreviations: $\mathrm{CHF}=$ congestive heart failure; $\mathrm{MI}=$ myocardial infarc tion; CVA = cerebrovascular accident; TIA = transient ischemic attack.

* Data are expressed as percentage of group with each characteristic.

or akinesis associated with a diastolic contour abnormality in the setting of acute anterior transmural myocardial infarction. They found a 6.7 -fold greater 1-year mortality rate $(61 \%$ vs $9 \%$ ) in those patients whose infarctions were associated with acute LVA formation as compared to those patients whose infarctions were not. The Meizlish study differs from the Faxon study, as well as the present study, because it examines patients with acute (not remote) infarction, it uses nuclear (not angiographic) techniques, and it uses a different definition of LVA. The present study adds to these earlier studies by examining the cardiac morbidity as well as the mortality rate associated with LVA by assessing the effectiveness of surgical resection in a controlled (albeit nonrandomized) fashion and by restricting the control group to those with discrete segmental abnormalities.

The central issue of this study is of significant interest since the traditional therapy of LVA, that is, aneurysmectomy, is of unproved efficacy and is associated with a high operative mortality rate $(3.3 \% \text { to } 50 \%)^{9}{ }^{914,15,18,22} 24$ Furthermore, the results of many studies on the effectiveness of surgical resection on cardiac morbidity and mortality are highly variable, uncontrolled, and usually complicated by concomitant revasularization. . 12-20 $^{9}$

The definition of LVA in the literature has been quite variable, with debate focusing on the degree of the necessary wall motion abnormality, $4,5,16,21$ the diastolic contour, , 18, 21 histologic composition, ${ }^{1,7}$ wall thickness, and discreteness of its margins. ${ }^{4}$ Much of this disagreement is related to the inherent differences between clinical, surgical, and pathologic studies. Clearly, the definition of the term "left ventricular aneurysm" is not as important as the definition of specific abnormalities of left ventricular function which identify a subset of patients with distinctive clinical and hemodynamic characteristics.

For the purpose of this study, LVA is used to
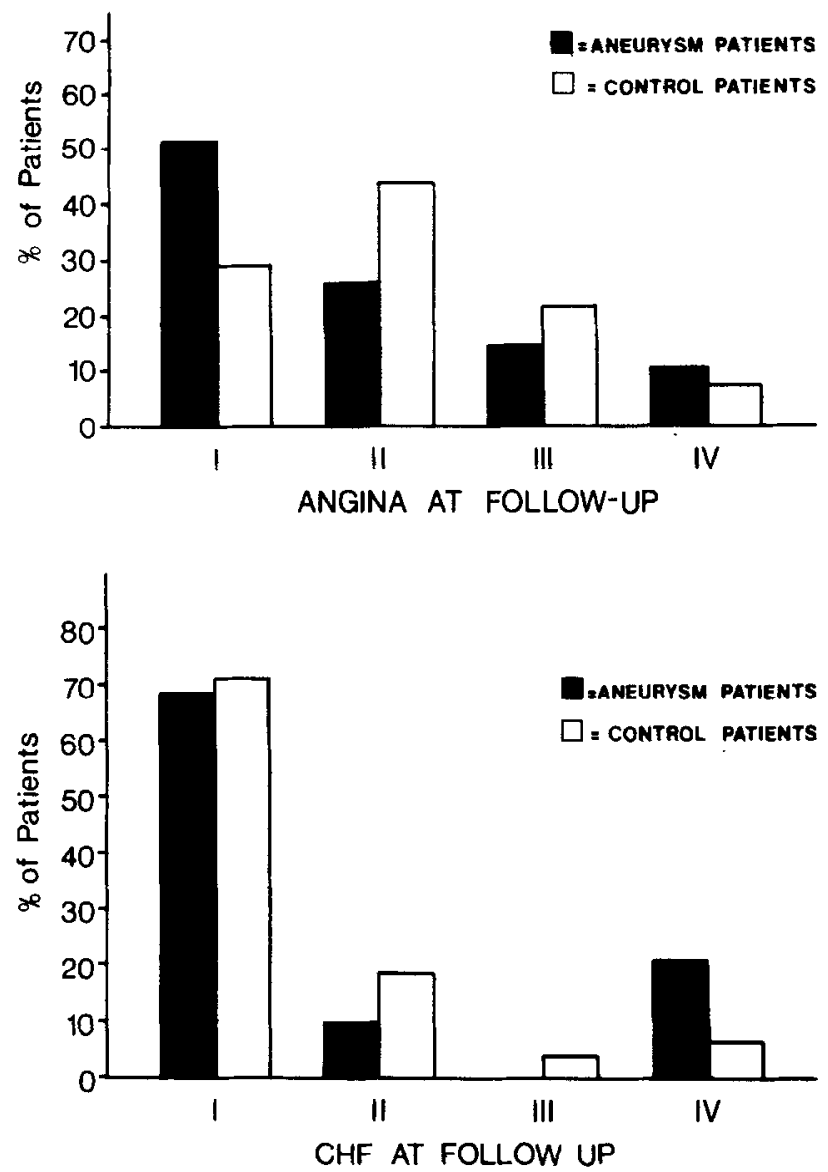

Fig. 3. Severity of symptoms of aneurysm patients (solid bars) and control patients (open bars) at the time of latest follow-up. Patients who died during the follow-up period are classified according to the most recent status while alive. Upper, Severity of angina (New York Heart Association Classification). Lower, Severity of congestive heart failure (New York Heart Association classification). None of the observed differences between the two groups is statistically significant.

describe a segment of the left ventricle which is dyskinetic at rest during ventriculography. The control group contained patients with one or more segments revealing akinesis (but no dyskinesis) and an ejection fraction less than $60 \%$. A population of patients with akinesis was chosen as a control group for two reasons. A regional wall motion abnormality was needed in this group in order to provide a population with a reduced mean ejection fraction comparable to that of the LVA group while excluding those patients with primary (and more likely global) myocardial disease who might have a different natural history than those with ischemic (and more likely segmental) myocardial disease. Akinesis was chosen as the necessary abnormality in the control group in order to provide a population of 
patients for comparison with as severe a regional abnormality as possible short of LVA. If patients in the control group with high ejection fractions were not excluded, the less severe regional abnormality present in this group would have resulted in a higher mean ejection fraction than in the LVA group. Since ejection fraction is known to have major prognostic significance, failure to have comparable mean ejection fractions in the two groups would have made conclusions about the prognostic significance of LVA impossible. Whether the lower mean ejection fraction in the LVA group (prior to the previously mentioned exclusions) can be attributed solely to the systolic expansion of the aneurysm or is, in part, the result of a greater degree of overall left ventricular dysfunction cannot be ascertained from this study.

Morbidity of left ventricular aneurysm. The major clinical problems most frequently attributed to LVA are congestive heart failure, malignant ventricular arrhythmias, thromboembolic phenomena, and an increased mortality rate. This study provides evidence that patients with LVA are at no more risk for these problems than are patients with similar ejection fractions and coronary artery disease but who are free of LVA.

The reported incidence of congestive heart failure in patients with LVA ranges from $21 \%$ to $86 \% .^{1,7,9-11}$ In this study, $32 \%$ of patients with LVA had congestive heart failure, which was not statistically different from the incidence of $29 \%$ in the control group. This finding suggests that the experimental ${ }^{24}$ and theoretic ${ }^{25}$ hemodynamic burden imposed by an expansile segment of the left ventricle may be clinically important only insofar as it reduces the overall ejection fraction.

Thromboembolic phenomena have frequently been reported to be associated with LVA, the incidences ranging from $0 \%$ to $20 \%$ in clinical studie $^{5,10,11}$ and $9 \%$ to $52 \%$ in pathologic studies., ${ }^{1,7}$ The frequent discrepancy between clinical and pathologic studies may reflect either the high incidence of clinically occult emboli, the failure to recognize a vascular event as embolic in nature, or the inherent differences in patient populations. None of the patients in this study was anticoagulated, and none had a clearly embolic event. There are several cerebrovascular events in both groups, but all of these were clinically or angiographically believed to be the result of intrinsic cerebrovascular disease.

With the widespread emergence of endocardial mapping and other invasive electrophysiologic studies, ${ }^{17,26}$ new antiarrhythmic agents, and surgical treatment of ventricular arrhythmias, ${ }^{9,12,13,26}$ there is much interest in the identification of patients at high risk for malignant arrhythmias. ${ }^{8,17}$ Malignant arrhythmias have been reported to occur in $14 \%$ to $40 \%$ of patients with LVA. ${ }^{7.10}$ Whether this incidence is a reflection of a peculiar property of LVA or simply a manifestation of the severe underlying heart disease has not yet been addressed. The results of this study support the latter view in that the incidence of ventricular tachycardia and fibrillation was not significantly different between the two groups. It must be acknowledged, however, that ambulatory monitoring was not routinely performed and that there was a trend (which fails to reach statistical significance) toward more ventricular tachycardia in the LVA group. This observation is in agreement with another recent study addressing this issue. $^{8}$

Death from LVA. The mortality rates were high in each group but not significantly different from each other. In comparison with the study by Faxon et al., ${ }^{4}$ in which the mean ejection fraction among patients with LVA was similar to that of this study, the present mortality rate was somewhat higher $(38 \%$ over 33 months compared to $21 \%$ over 36 months). This may reflect differences in the timing of the index catheterization, the slightly higher mean age and higher incience of congestive heart failure in this study, or a reflection of the difference in definition of LVA. Nevertheless, this study agrees with the conclusion of the Faxon study that LVA does not increase the mortality rate independent of overall left ventricular function. These conclusions are in sharp contrast to those of the study by Meizlish et al. ${ }^{21}$ It may be that LVA is associated with an increased mortality rate during the first year of its formation but not thereafter. Alternatively, the differences may reflect the use of nuclear techniques to make the diagnosis of LVA which, in the present study, is very specific but not very sensitive when compared to angiographic techniques. The mortality figures from other studies of LVA are highly variable and uncontrolled, with most of the earlier studies showing much higher mortality rates, such as $73 \%$ in 3 years, ${ }^{1,28} 73 \%$ at 5 years, ${ }^{6}$ or an average postmyocardial infarction survival rate of only 4.8 years. ${ }^{29}$

Another interesting finding was that the 12 patients who underwent either aneurysmectomy or aneurysmorrhaphy did not demonstrate any significant functional advantage over those 26 patients in whom these procedures were not performed and, in fact, had 
a much higher mortality rate. Although these numbers are small, the data retrospective, and the patients nonrandomized, this is the first published series of surgical therapy in which a control group of unresected patients is available for comparison.

Clinical characteristics of LVA. It is interesting that clinical differentation between the two groups was not reliably possible, even with the use of noninvasive diagnostic studies. Two-dimensional echocardiography, electrocardiography, and radionuclide ventriculography were reasonably specific $(67 \%$, $85 \%$, and $92 \%$, respectively) but had surprisingly low sensitivities $(67 \%, 41 \%$, and $48 \%$, respectively). This contrasts with the results of other studies on the utility of these techniques in the diagnosis of LVA. ${ }^{30-33}$

The higher mean left ventricular end-diastolic pressure in the LVA group was statistically significant and seems to indicate decreased diastolic compliance of the aneurysmal left ventricle, since the mean ejection fraction and mean cardiac index were not significantly different between the two groups. This property is in obvious contrast to the higher systolic compliance of a dyskinetic segment when compared to an akinetic one. This finding is in agreement with an earlier study by Klein et al. ${ }^{26}$

There was an interesting, although not statistically significant, trend toward less severe coronary artery disease, less angina, and fewer bypassed vessels in the patients with LVA. Another interesting observation is that, despite the similar distribution of coronary artery disease (including the left anterior descending artery) in the two groups, there was a striking predilection for aneurysms to involve the apical segment of the left ventricle. Eighty-five percent of the aneurysms involved this segment compared to only $43 \%$ of the akinetic segments in the control group. This predilection is in agreement with many other studies., ${ }^{1,9,16,18}$ Whether or not these observed differences in hemodynamics, coronary disease, and distribution of segmental dysfunction between these two groups are identifying distinct subsets of patients remains to be determined.

In summary, this study suggests that LVA, in patients with coronary artery disease, is not a significant risk factor for cardiac morbidity or mortality when compared with patients without aneurysms but with similar degrees of left ventricular dysfunction as measured by ejection fraction.

We thank Mr. Kenneth Guire and Dr. Sylvia WasserfieldSmoller for their assistance with statistical analyses, Ms. Diane Bauer for her assistance in preparation of the manuscript, and
Ms. Nancy Bates for her assistance in the preparation of the illustrations.

\section{REFERENCES}

1. Schlichter J, Hellerstein HK, Katz LN: Aneurysm of the heart: A correlative study of one hundred and two proved cases. Medicine 33:43, 1954.

2. Cheng TO: Incidence of ventricular aneurysm in coronary artery disease: An angiographic appraisal. Am J Med 50:340, 1971.

3. Abrams DL, Edelist A, Luria WH, Miller AJ: Ventricular aneurysm: A reappraisal based on a study of sixty-five consecutive autopsied cases. Circulation 27:164, 1963.

4. Faxon DP, Ryan TJ, Davis KB, McCabe CH, Myers W, Lesperance J, Shaw R, Tong TG: Prognostic significance of angiographically documented left ventricular aneurysm from the coronary artery surgery study (CASS). Am $\mathbf{J}$ Cardiol 50:157, 1982.

5. Gorlin R, Klein MD, Sullivan JM: Prospective correlative study of ventricular aneurysm: Mechanistic concept and clinical recognition. Am J Med 42:512, 1967.

6. Dubnow MH, Burchell HB, Titus JL: Postinfarction ventricular aneurysm: A clinicomorphologic and electrocardiographic study of eighty cases. AM HEART J 70:753, 1965.

7. Hochman JS, Platia EB; Bulkley BH: Endocardial abnormalities in left ventricular aneurysms: A clinicopathologic study. Ann Intern Med 100:29, 1984.

8. Cohen M, Wiener I, Pichard A, Holt J, Smith H, Gorlin R: Determinants of ventricular tachycardia in patients with coronary artery disease and ventricular aneurysm: Clinical, hemodynamic, and angiographic factors. Am J Cardiol 51:61, 1983.

9. Codini MA, Ruggie NT, Goldin MD, Messer JV, Najafi H: Diaphragmatic left ventricular aneurysm: Clinical features, surgical treatment, and long-term follow-up in 22 patients. Arch Intern Med 142:711, 1982.

10. Grondin P, Kretz JG, Bical O, Donzeau-Gouge P, Petitclerc $R$, Campeau L: Natural history of saccular aneurysms of the left ventricle. J Thorac Cardiovasc Surg 77:57, 1979.

11. Gay WA: Management of ventricular aneurysms following myocardial infarction. World J Surg 2:743, 1978.

12. Mason JW, Stinson EB, Winkle RA, Oyer PE, Griffin JC, Ross DL: Surgery for ventricular tachycardia: Efficacy of left ventricular aneurysm resection compared with operation guided by electrical activation mapping. Circulation 65:1148, 1982.

13. Martin JL, Untereker WJ, Harken AH, Horowitz LN, Josephson ME: Aneurysmectomy and endocardial resection for ventricular tachycardia: Favorable hemodynamic and antiarrhythmic results in patients with global and ventricular dysfunction. AM HEART J 103:960, 1982.

14. Brawley RK, Magovern GJ, Gott VL, Donahoo JS, Gardner TJ, Watkins L Jr: Left ventricular aneurysmectomy: Factors influencing postoperative results. I Thorac Cardiovasc Surg 85:712, 1983 .

15. Kiefer SK, Flaker GC, Martin RH, Curtis JJ: Clinical improvement after ventricular aneurysm repair: Prediction by angiographic and hemodynamic variables. J Am Coll Cardiol 2:30, 1983.

16. Cohen M, Packer M, Gorlin R: Indications for left ventricular aneurysmectomy. Circulation 67:717, 1983.

17. Wiener I, Mindich B, Pitchon R: Determinants of ventricular tachycardia in patients with ventricular aneurysms: Results of intraoperative epicardial and endocardial mapping. Circulation 65:856, 1982.

18. Burton NA. Stinson EB, Oyer PE, Shumway NF: Left ventricular aneurysm: Preoperative risk factors and longterm postoperative results. J Thorac Cardiovasc Surg 77:65, 1979 . 
19. Sesto M, Schwarz F, Thiedemann K-U, Flameng W, Schlepper M: Failure of aneurysmectomy to improve left ventricular function. Br Heart J 41:79, 1979.

20. Froehlich RT, Falsetti HL, Doty DB, Marcus ML: Prospective study of surgery for left ventricular aneurysm. Am J Cardiol 45:923, 1980 .

21. Meizlish JL, Berger HJ, Plankey M, Errico D, Levy W, Laret BL: Functional left ventricular aneurysm formation after acute anterior transmural myocardial infarction: Incidence. natural history, and prognostic implications. N Engl J Med 311:1001, 1984.

22. Rittenhouse FA, Sanvage I,R, Mansfield PB, Smith IC, Davis CC, O'Brien MA: Results of combined left ventricular aneurysmectomy and coronary artery bypass: 1974-1980. Am J Surg 143:575, 1982.

23. Kapelanski DP, Al-Sadir J, Lamberti JJ, Anagnostopoulos CE: Ventriculographic features predictive of surgical outcome for left ventricular aneurysm. Circulation 58:1167, 1978.

24. Mullen DC, Posey L, Gabriel R, Singh HM, Flemma RJ, Lepley D Jr: Prognostic considerations in the management of left ventricular aneurysms. Ann Thorac Surg 23:455, 1977.

25. Tyson K, Mandelbaum I, Shumacker HB Jr: Experimental production and study of left ventricular aneurysms. J Thorac Cardiovase Surg 44:731, 1962.
26. Klein MD, Herman MV, Gorlin R: A hemodynamic study of left ventricular aneurysm. Circulation 35:614, 1967.

27. Horowitz LN, Harken AH, Josephson ME, Kastor JA: Surgical treatment of ventricular arrhythmias in coronary artery disease. Ann Intern Med 95:88, 1981.

28. Schattenberg TT, Giuliani ER, Campion BC, Danielson GB; Postinfarction ventricular aneurysm. Mayo Clin Proc 45:13, 1979.

29. Davis RW, Ebert PA: Ventricular aneurysm: A clinical. pathologic correlation. Am J Cardiol 29:1, 1972.

30. Rigo P, Murray M, Strauss HW, Pitt B: Scintiphotographic evaluation of patients with suspected left ventricular aneurysm. Circulation 50:985, 1974.

31. Vissner CA, Kan G, David GK, Lie KI, Durrer D: Echocardiographic-cineangiographic correlation in detecting ventric ular aneurysm: A prospective study of 422 patients. Am J Cardiol 50:377, 1982.

32. Baur HR, Daniel JA, Nelson RR: Detection of left ventricular aneurysm on two-dimensional echocardiography. Am $J$ Cardiol 50:191, 1982.

33. Weyman AE, Peskoe SM, Williams ES, Dillon JC, Feigenbaum $\mathrm{H}$ : Detection of left ventricular aneurysms by cross. sectional echocardiography. Circulation 54:936, 1976.

\title{
Increased left ventricular volume following myocardial infarction in man
}

\begin{abstract}
To determine the relationship between left ventricular volumes and the magnitude of wall motion abnormality in the chronic post myocardial infarction period, the right anterior oblique left ventriculogram was analyzed in $\mathbf{5 5}$ patients with left anterior descending coronary artery disease. The size of the infarct segment was determined by measuring the percentage of the circumference of the left ventricular silhouette that was akinetic and/or dyskinetic. Four groups of patients were defined with increasing degrees of wall motion abnormality based on the percent of the diastolic perimeter that was akinetic and/or dyskinetic. Marked increases in end-diastolic and end-systolic volumes were observed across groups of increasing wall motion abnormality. These large increases in volume could not be accounted for by an increase in filling pressures. Ejection fraction fell in proportion to the increase in wall motion abnormallty across groups. This study demonstrated that in the chronic phase of infarction, left ventricular remodeling results in alterations in left ventricular volumes that are proportional to the degree of wall motion abnormality. (AM HEART J 111:30, 1986.)
\end{abstract}

Gervasio A. Lamas, M.D., and Marc A. Pfeffer, M.D., Ph.D. Boston, Mass.

From the Cardiovascular Division, Department of Medicine, Brigham and Women's Hospital, Harvard Medical School.

Supported in part by a grant from the National Heart, Lung, and Blood Institute of the National Institutes of Health, No. HL28238. Dr. Lamas received support from the National Institutes of Health Training Grant No. HL 07049. Dr. Pfeffer is the recipient of an Established Investigatorship of the American Heart Association, Inc.

Received for publication Jan. 4, 1985; revision received June 20, 1985; accepted July 22,1985

Reprint requests: Marc A. Pfeffer, M.D. Cardiovascular Division, Brigham and Women's Hospital, 75 Francis St.. Boston, MA 02115.
The presence of cardiomegaly in patients with coronary artery disease portends a grave prognosis. ${ }^{1-4}$ The development of cardiac enlargement following a myocardial infarction is generally thought to be a complication limited to patients with extensive infarctions. The clinical and roengtenographic recognition of cardiac enlargement is generally recognized as insensitive and would be expected to detect only marked ventricular enlargement. Notwith- 